\title{
Investigating the effects of rehabilitation and the use of curved-integrated members on the behavior of chairs
}

\author{
Mahmoud-Reza Hosseini-Tabatabaei ${ }^{1}$, Ali Bayatkashkoli², Mahmoud Reza Mollaeinia ${ }^{1 *}$, Farhad Kool², \\ Mohsen Rahmani Ardakani and Narjes Khaton Madahi ${ }^{2}$
}

\begin{abstract}
Expanding the service life length of wooden made furniture, and consequently decreasing the demand for raw wood could help the economy of the world society and environmental safety. In this research, an experimental inquiry was conducted to determine the effects of curved members, the frame integrity, chair scheme, and rehabilitation of even the failed chairs on the behavior of chairs. The flexural properties of the curved specimens were firstly determined using the ASTM D143-94 test. Then, three layouts of chairs (A, B, and C) made from poplar wood were examined under the DIN EN-1729-1\&2 standard. Finally, the failed chairs were rehabilitated using the sheets of glass fiberreinforcing polymers (GFRP) and re-tested. The results showed that the rehabilitation of the curved samples causes rebounding of their mechanical properties. Besides, the rehabilitated samples are more flexible than primary ones. Furthermore, the results demonstrate that the capability of the proposed normalized modulus of rupture (NMOR) criterion, in contrast to the current modulus of rupture (MOR) one, for predicting the failure modes and regions of the wooden and composite structures. The experiments on the chairs showed that all rehabilitated patterns are more robust than primary schemes. That means, the discarded (or discarding) chairs (due to failure of joints, legs, or, in general, a part of the chairs) return to their service life, and massively reduce the demand for wood, which is strongly favored by environmental aspects. Moreover, rehabilitated layout B (RB), which has two continuous-main-curved members is at least 2.4 times stronger than other rehabilitated patterns, and rehabilitated layout $C$ (RC) having three continuous-main-curved members is about $40 \%$ stronger than a rehabilitated custom chair (RA), that illustrates more integrity and strength. Besides that, the strength of RB is 2.22 and 2.04 times that of the corresponding primary chairs, depending on front-to-back and up-to-down loading, respectively. Finally, univariate analyses of variance and least significant difference (LSD) showed the high precision of the results. Consequently, the research provides a facility not only to save original material resources, but also to eliminate furniture waste going in the landfill.
\end{abstract}

Keywords: Poplar-wooden chairs, Integrated-curved members, Chair rehabilitation, Rebounding mechanical properties, Glass fiber-reinforced polymers, Service life length

\section{Introduction}

Over the past decade, increasing demand for wooden products and adversely decreasing the supply of raw materials has encouraged scientists to present such

\footnotetext{
*Correspondence: m_mollaienia@uoz.ac.ir; mmollaienia@gmail.com ${ }^{1}$ Department of Civil Engineering, The College of Technology and Engineering, University of Zabol, P. O. Box: 98615-119, Zabol, Iran Full list of author information is available at the end of the article
}

designs of furniture, which make it possible to expand the length of furniture service life and ultimate strength of chair frames [1-3]. The length of furniture service life, usually, decreases due to mechanical failure of even a leg, rail or joint, and/or more often a loose joint [4, 5], whereas most of the frames' members have powerfully stayed intact [1]. It seems, therefore, the service life of the furniture could be increased by rehabilitating with materials of higher quality, replacing or recycling 
damaged parts. From the designing point of view, supplying an efficient preplan would provide the ease of disassembling and partial repairing or replacing.

There exists different pattern for chairs. The custom chairs usually are constructed from several members connected by screwed or glued joints. The kind and number of joints affect the mechanical strength, performance, and service life of a chair made from poplar wood. To enhance these characteristics of the frames, designers (1) may remove some of the frame's joints, or (2) may use stretchers (box stretcher or cross stretcher), wood shelf brackets, or curved-continuous elements.

In the conventional poplar wood chairs, the elements glued together often separate at the glued lanes within the mortise or finger joints [1]. Also, the failure of the custom chair most frequently occurs between the back post and the seat rail, while the use of stretchers and brackets-transmits the failure location to the joints between the back/front post and the side rail. Additionally, the frames produced by curved elements mostly fail at curvature turning regions [2]. The locations of the chair components prone to failure can be reinforced, or the harmed parts can be rehabilitated, generally, using timber tends of composite materials such as fiber-reinforcing polymers (FRP), carbon fiber-reinforcing polymers (CFRP), [6], or glass fiber-reinforcing polymers (GFRP) [7]. Glass and carbon fibers reinforcing materials are lightweight and widely available. They have high toughness, low density, low cost, and excellent thermal properties [8]. Carbon fibers significantly improved the shear strength of bond layers between wood ends. The tensile strength of a reinforced wood member is up to, or even more than, twice the strength of corresponding un-reinforced members [9].

The main advantages that may cause more widespread application of glass fibers are high tensile strength, stiffness, resistance to chemical harm, and excellent insulating properties $[10,11]$. Connection strength grows up as the number of layers of fiberglass increases. The ultimate strength of a three-layer-reinforced connection was $33 \%$ greater than the non-reinforced joint for parallel-to-grain loading and more than twice the strength for perpendicular-to-grain loading [12].

There exist few studies for reuse and rehabilitation of chair frames $[3,6,13]$. In this research, we empirically and numerically investigated the effects of rehabilitation by GFRP sheets, chairs' layout, the integrity of their members on the chair frames, and the behavior of their components. For this purpose, three various layouts of chairs were designed, constructed, and examined by standard tests. Then their harmed locations were rehabilitated by GFRP sheets and re-tested.
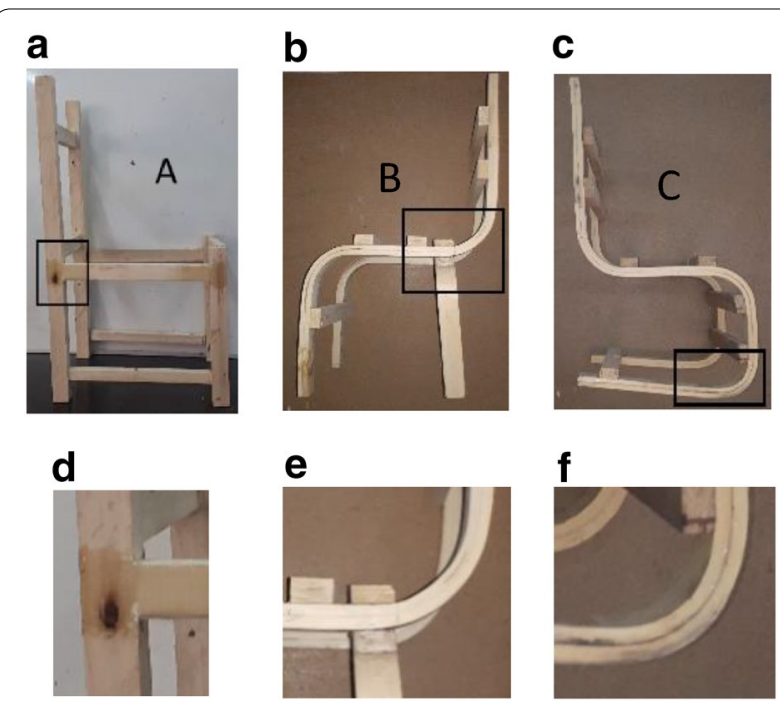

e

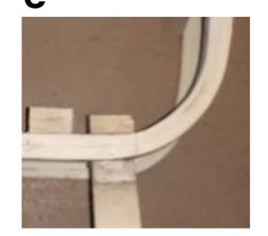

f

Fig. 1 a Layout A, custom chair; $\mathbf{b}$ Layout B, the chair having three main-curved members; $\mathbf{c}$ Layout $\mathrm{C}$, the chair having two main-curved members, and $\mathbf{d}-\mathbf{f}$ their corresponding regions prone to failure

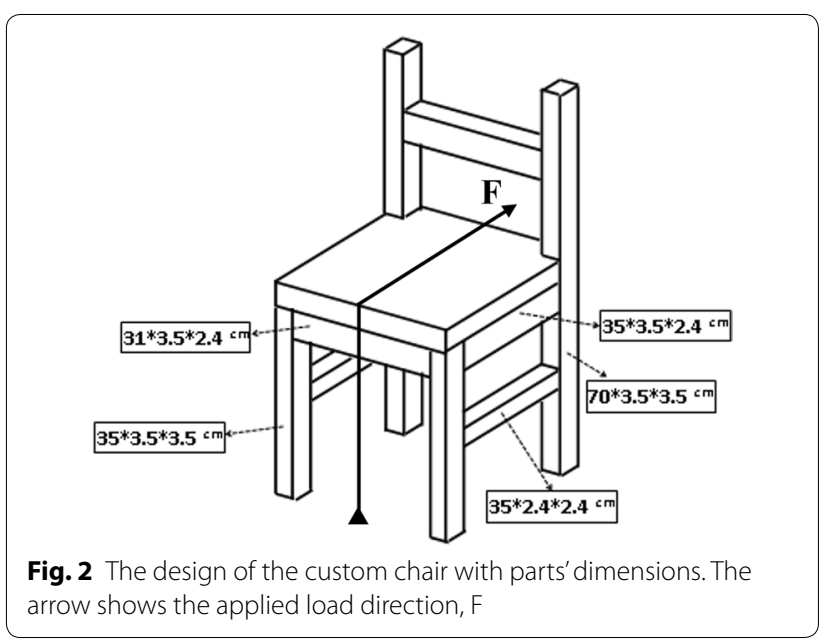

A comparison was conducted between primary and rehabilitated chairs' behavior.

\section{Materials and methods}

Manufacturing of custom and curved chairs (the assembly of the seats)

In this study, chairs were made from Poplar (Populus nigra) species in three different patterns including the custom chair (layout A, Fig. 1A), layout B having three integrated-curved members (Fig. 1B), and layout $C$ having two-curved members (Fig. 1C). The dimensions of the custom chair and its components, shown in Fig. 2, were adapted from published data [14-16] and the DIN EN 1729-1 [17]. Custom chairs were constructed with 
Table 1 The characteristics of the polyvinyl acetate glue

\begin{tabular}{ll}
\hline Properties & Test result \\
\hline Appearance & $\begin{array}{c}\text { Milky white, smooth, and free of } \\
\text { foreign particles }\end{array}$ \\
$\mathrm{pH}$ & 3.2 \\
Film-forming properties & Smooth, colorless, and transparent \\
Minimum film-forming temperature & $20^{\circ} \mathrm{C}$ \\
Storage time & 6 months \\
Solid materials & $32 \%$ \\
Assembly time & 10 min \\
Preparation & Not need \\
\hline
\end{tabular}

stretchers, tenon, and mortise joint, while for construction of the curve-frame chairs, the curved members were connected to each other or side stretchers by glue and stainless screws having $40 \mathrm{~mm}$ lengths and $4 \mathrm{~mm}$ diameter.

Polyvinyl acetate glue was used as the adhesive, detailed in Table 1. For ultimately consolidating the joints and GFRP timbers, the assembled chairs were maintained at normal atmospheric conditions for a time of $24 \mathrm{~h}$. Each treatment was done with three replications.

\section{Rehabilitation of chair frames}

The primary wooden chairs crumbled due to the loosening or separation of the frames' joints or the failure of the curved members in curved regions, under the ultimate load. We rehabilitated the harmed parts in the following way:

1. The surfaces of the damaged area were smoothed and cleaned,

2. The unsaturated polyester resin containing curing additives was spread over the surfaces using knives having flexible-blade,

3. The glass fiber was placed on the resin and was wetted,

4. A sealer layer of the resin was poured on the fiber, and

5. The chairs' frames were coated by GFRPs and were cured at $60^{\circ} \mathrm{C}$ for $24 \mathrm{~h}$. During the curing, the pressure was not employed on the surfaces. Just a 1-ply sheet of glass fiber was saturated by epoxy resin.

The product of E-glass fiber used for rehabilitation is Kor-GFW420 (Korea RE\&T, Korea) having strength and stiffness, areal weight, and thickness of $2300 \mathrm{MPa}, 76$ $\mathrm{GPa}, 420 \mathrm{~g} / \mathrm{m}^{2}$, and $0.16 \mathrm{~mm}$, respectively. The employed epoxy resin EPIKOTE 828 (Hexion, Germany) has a medium viscosity liquid epoxy resin produced from Biphenyl A and Epichlorohydrin. The product name of hardener was EPIKURE F205 (Hexion, Germany) that has a low viscosity, modified cycloaliphatic amine curing agent. The weight ratio of epoxy resin to hardener was 10:5.8.

\section{The methodology and the experimental studies}

A comparison was conducted between the performances of the rehabilitated-specimen and original specimen, first, to study the behavior of the curved members used in chair patterns. Then, three chairs from each layout A, $\mathrm{B}$, and $\mathrm{C}$ were constructed and evaluated under front-toback loading (FtoBL) and three more replications from pattern $\mathrm{C}$ evaluated under top-to-down loading (TtoDL), as tabulated in Table 2. The standard test of the DIN EN-1729-2 [18], by Universal Testing Machine (UTM), was applied for illustrating the behavior of the chairs. Chair loading was continued until it reached the ultimate load at which the chair failed due to the loosening of conjunctions, separation of the joints, or the damage of curved members. The failed chairs were rehabilitated by the method revealed in the previous sub-section. Finally, the statistical analysis of the data was run by the SPSS package program. A one-way analysis of variance (ANOVA) was performed on the data. The differences between means values were derived according to the Least Significant Difference (LSD) test at a 95\% level of protection.

\section{Implementation of the specimen test}

The failure modes of specimens under compressive load are profoundly different depending on the loading direction [19]. In this research, we applied specimens with small grain angles. All curved specimens, manufactured from poplar wood, which was defect-free and straightgrained, include two glued pieces which were modified with thermal treatment (Fig. 3a, b). The specimens were put in the compressive test machine consistent with the loading model illustrated in Fig. 3c, and their flexural properties were determined according to the standards ASTM D143-94 [20] by a computer-controlled INSTRON machine, Model DANP4.

Table 2 Classification of the chairs

\begin{tabular}{llll}
\hline $\begin{array}{l}\text { Chairs } \\
\text { layouts }\end{array}$ & $\begin{array}{l}\text { Number } \\
\text { of replications }\end{array}$ & $\begin{array}{l}\text { The group } \\
\text { of primary chairs }\end{array}$ & $\begin{array}{l}\text { Corresponding } \\
\text { rehabilitated } \\
\text { chairs }\end{array}$ \\
\hline A & 3 & PA-FtoBL & RA-FtoBL \\
B & 3 & PB-FtoBL & RB-FtoBL \\
C & 3 & PC-FtoBL & RC-FtoBL \\
& 3 & PC-UtoDL & RC-UtoDL \\
\hline
\end{tabular}



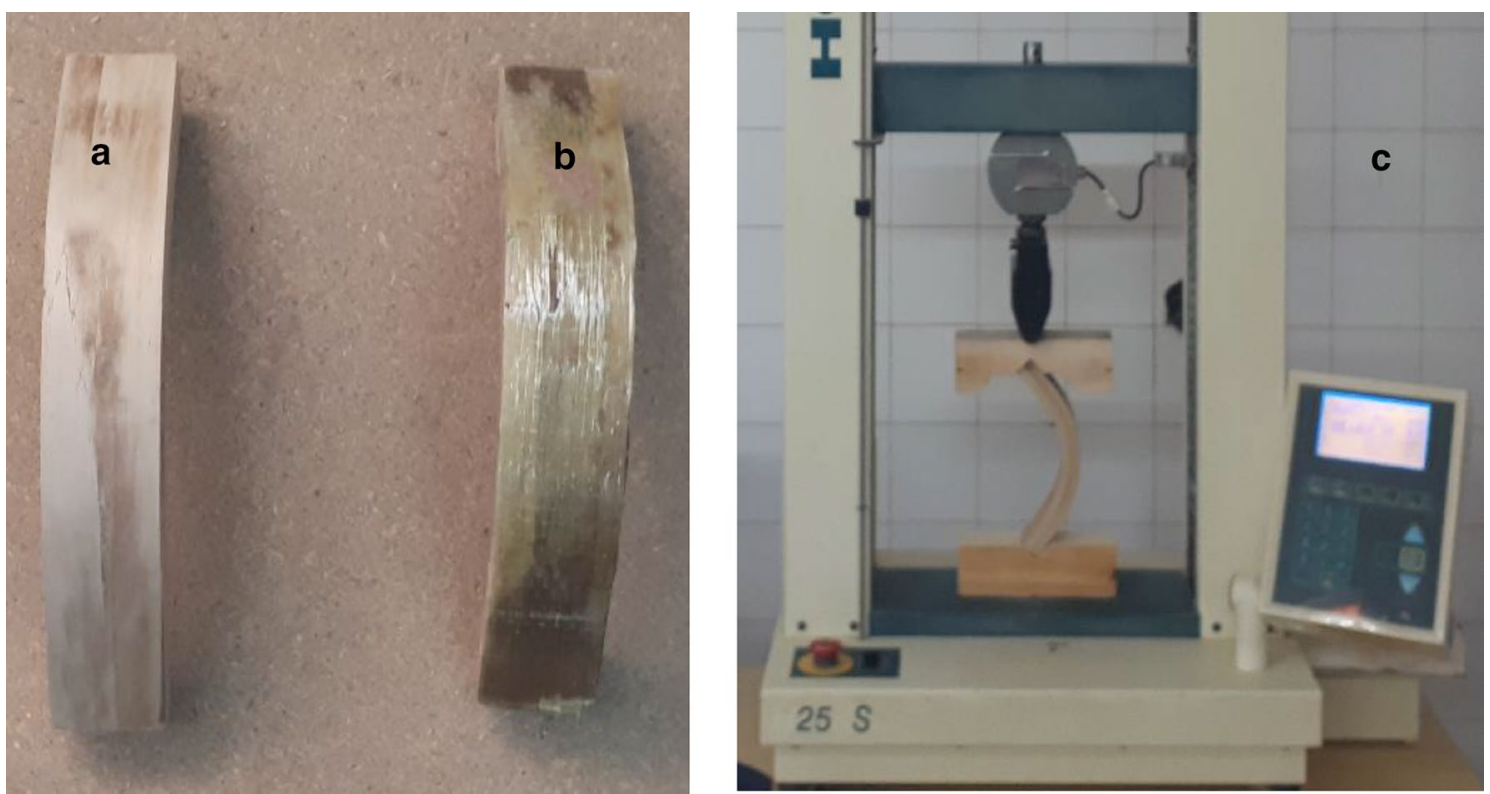

Fig. 3 a Primary-curved sample, $\mathbf{b}$ rehabilitated-curved sample with GFRP), and $\mathbf{c}$ the schematic illustration of the compression test

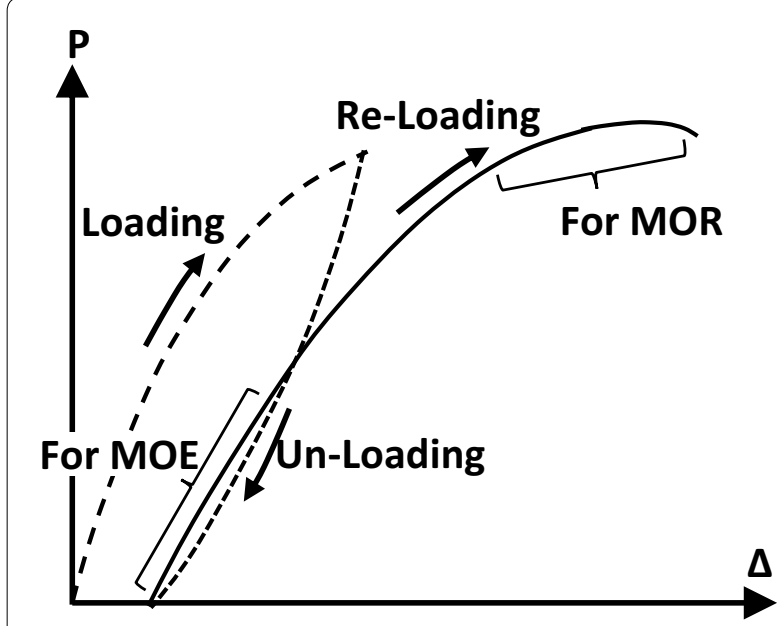

Fig. 4 The loading cycle of a sample

\section{The evaluation criteria of the specimens' behavior}

The specimen performance was evaluated by the modulus of elasticity (MOE) and modulus of rupture (MOR). For the determination of MOE and MOR, initially, the primary-curved sample was loaded until its failure was detected. Then, the damaged sample was rehabilitated by GFRP and evaluated in the same manner. Therefore, the process has three steps that include loading, unloading, and reloading, shown in Fig. 4.

The curvature radius of the samples is constant, and their formatting angle is 90 degrees. They have a height of $85 \mathrm{~mm}$, a width of $45 \mathrm{~mm}$, and a thickness of crosssection of $25 \mathrm{~mm}$. We assume the supports at both ends of the specimen are simple, and their moments are ignorable. Thus, one could readily obtain MOR and MOE by applying equilibrium equations and energy methods, respectively.

\section{The MOE and MOR formulation for primary-curved} specimens

To determine MOE and MOR, for a primary-curved specimen, one could write,

$$
\begin{aligned}
& M_{\theta}=P R \sin \theta, m_{\theta}=R \sin \theta \\
& M_{\max }=P R \Rightarrow \sigma_{\max }=\frac{(P R)(h / 2)}{b h^{3} / 12} \Rightarrow \\
& \operatorname{MOR}=\frac{6 p_{\mathrm{U}} R}{b h^{2}} \\
& \Delta=\int_{0}^{\pi} \frac{M_{\theta} m_{\theta}}{E I} R d \theta=2 \int_{0}^{\pi / 2} \frac{M_{\theta} m_{\theta}}{E I} R d \theta \\
& =\frac{2 P R^{3}}{E I} \int_{0}^{\pi / 2} \sin ^{2} \theta d \theta \Rightarrow \\
& \Delta=\frac{\pi P R^{3}}{2 E I}=\frac{6 \pi P R^{3}}{E b h^{3}} \Rightarrow \\
& \mathrm{MOE}=\frac{6 \pi P_{\mathrm{PL}} R^{3}}{\delta_{\mathrm{PL}} b h^{3}},
\end{aligned}
$$




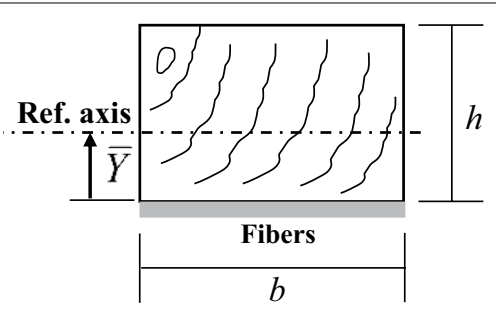

Fig. 5 The rehabilitated cross-section applied for calculating MOE

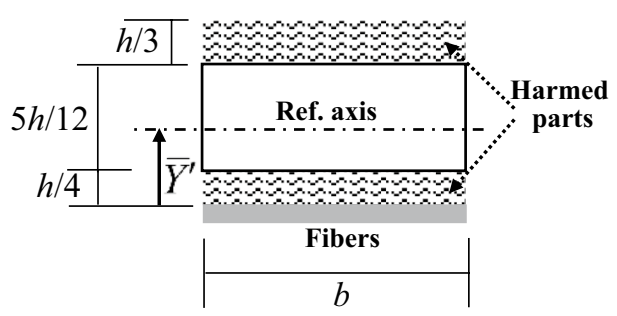

Fig. 6 The rehabilitated cross-section used for calculating MOR

in which $P$ is the overburden load, $\sigma_{\max }$ is the maximum normal stress due to maximum bending moment $\left(M_{\max }\right), \mathrm{EI}$ is flexural rigidity, MOR is the modulus of rupture, MOE is the modulus of elasticity, $M_{\Theta}$ is the moment function, $m_{\mathrm{e}}$ is moment function subjected to unit load, $P=1, \Delta$ the displacement, $\delta_{\mathrm{PL}}$ is displacement corresponding to the proportional limit load, $P_{\mathrm{PL}}$ is the proportional limit load, $P_{\mathrm{U}}$ is the ultimate (maximum) load, $b$ is the width of the cross-section, $h$ is the thickness (the height of the cross-section), and $R$ is the curvature radius.

\section{The MOE and MOR formulation for rehabilitated-curved specimens}

Despite that the entire cross-section being used to calculate MOE, see Fig. 5, the damaged portions of the cross-section were not considered for deriving MOR, which may include an area with a) height of $h / 3$ from the farthest compressive fiber and b) height of $h / 4$ from the farthest stretch-fiber (Fig. 6). For determination of MOE, one could write,

$$
\begin{aligned}
& \bar{Y}=\left(\frac{0.5 h}{1+n\left(t_{f} / h\right)}\right) \Rightarrow I_{e}=\left(\frac{b h^{3}}{12}\right) \\
& \left(1+3\left(\frac{n t_{f} / h}{\left.1+n t_{f} / h\right)}\right)^{2}\right)+\left(\frac{n b t_{f}}{4}\right)\left(\frac{h}{\left.1+n t_{f} / h\right)}\right)^{2} \\
& I_{e}=\left(\frac{b h^{3}}{12}\right)+b h(\bar{Y}-0.5 h)^{2}+n b t_{f} \bar{Y}^{2} \\
& \operatorname{MOE}^{\text {Rehab }}=\frac{\pi P_{P L} R^{3}}{2 I_{e}}
\end{aligned}
$$

where $t_{f}$ is the thickness of the GFRP layer, $\bar{Y}$ is the distance from the GFRP layer to the reference axis of the cross-section, the entire of which withstand tensile stress (Fig. 5), $n$ is the ratio of elastic modulus of GFRP to the wood's modulus of elasticity, $I_{e}$ is the equivalent moment of inertia for the whole cross-section, and Rehab. reveals the MOE is related to rehabilitated specimens.

The failure of a specimen may occur due to the tensile failure of GFRP and/or tensile or compressive failure of wood. Sometimes, the GFRP was debonded from the wood surface. In this research, the rehabilitated chair (a typical composite wooden structure) was made of different materials, GFRP and wood, with different strengths. Besides, the wood has different strengths under tensile and compressive stress. Therefore, we introduce a new criterion for evaluating the failure mode of a wooden structure that is called normalized MOR (NMOR). NMOR is a dimensionless parameter defining the ratio of MOR to the ultimate stress. There exist more detail in the sub-section of the evaluation of the specimens' behavior. We formulated NMOR as the following equations:

$$
\begin{aligned}
& \bar{Y}^{\prime}=\frac{2.3 h}{5+12 n\left(t_{f} / h\right)} \\
& I_{e}^{\prime}=0.006 b h^{3}+0.42 b h\left(\bar{Y}^{\prime}-0.208 h\right)^{2}+n b t_{f} \bar{Y}^{\prime 2} \\
& \operatorname{MOR}_{F-C}^{\text {Rehab. }}=\frac{n P_{\mathrm{U}} R \bar{Y}^{\prime}}{I_{e}^{\prime}}, \\
& \operatorname{MOR}_{W-C-\text { in Ten. }}^{\text {Rehab. }}=\frac{P_{\mathrm{U}} R\left(\bar{Y}^{\prime}-h / 4\right)}{I_{e}^{\prime}}, \\
& \operatorname{MOR}_{W-C-\text { in Comp. }}^{\text {Rehab. }}=\frac{P_{\mathrm{U}} R\left(2 h / 3-\bar{Y}^{\prime}\right)}{I_{e}^{\prime}}
\end{aligned}
$$

$$
\begin{aligned}
& \mathrm{NMOR}_{F-C}^{\text {Rehab. }}=\frac{n P_{\mathrm{U}} R \bar{Y}^{\prime}}{\sigma_{U F} I_{e}^{\prime}}, \\
& \mathrm{NMOR}_{W-C-\text { in Ten. }}^{\text {Rehab. }}=\frac{P_{\mathrm{U}} R\left(\bar{Y}^{\prime}-h / 4\right)}{\sigma_{\mathrm{U}-T-W} I_{e}^{\prime}}, \\
& \mathrm{NMOR}_{W-C-\text { in Comp. }}^{\text {Rehab. }}=\frac{P_{\mathrm{U}} R\left(2 h / 3-\bar{Y}^{\prime}\right)}{\sigma_{\mathrm{U}-C-W} I_{e}^{\prime}},
\end{aligned}
$$

$$
\begin{aligned}
& \mathrm{NMOR}_{C}^{\text {Rehab. }}=\max \left(\mathrm{NMOR}_{F-C}^{\mathrm{Reh} a b .},\right. \\
& \left.\mathrm{NMOR}_{W-C-\text { in Ten. }}^{\text {Rehab. }} \quad \mathrm{NMOR}_{W-C-\text { in Comp. }}^{\text {Rehab. }}\right),
\end{aligned}
$$

where $\bar{Y}^{\prime}$ is the distance from the GFRP layer to the reference axis of the cross-section, the harmed part of which has not been considered (Fig. 6), $I_{e}^{\prime}$ is the equivalent moment of inertia of the cross-section, the harmed 
Table 3 The mean values of the mechanical properties

\begin{tabular}{lrr}
\hline Mechanical parameters & \multicolumn{1}{c}{ The mean value of the parameter (土 Std. deviation) } \\
\cline { 2 - 3 } & Non-rehabilitated sample & Rehabilitated sample \\
\hline Maximum load (N) & $5030(165.0)$ & $5148(564)$ \\
MOE (MPa) & $12,002.5(2499)$ & $11,468.6(6432)$ \\
MOR (MPa) & $90.88(2.985)$ & $77.73(8.882)$ \\
MOR of the wooden member at tensile part (MPa) & & $126.4(14.44)$ \\
MOR of the wooden member at compressive part (MPa) & & $200.2(22.88)$ \\
MOR of the fiber (MPa) & $1.515(0.050)$ & $2.106(0.231)$ \\
NMOR of tensile part (MPa) & $2.330(0.077)$ & $1.993(0.218)$ \\
NMOR of compress part (MPa) & & $0.087(0.010)$ \\
NMOR of fiber part (MPa) & & \\
\hline
\end{tabular}

part of which has not been considered, $\sigma_{\mathrm{U}}$ is the ultimate stress, $C$ specifies Eqs. 4-6 are related to the compressive test, $F, W$ the denote the fiber and wood materials, respectively, inTen., inComp.: The area under tension and compressive stress, correspondingly.

Similarly, one can derive equations for when the specimen takes in the tension test, for this aim it is sufficient to multiply Eqs. 4 by $1 / 2$ and replace the suffix $C$ by $T$.

\section{The implementation of the chairs tests}

The chair was fixed such that it could not slip when the load was applying. The quantity of the load was gradually increased with a speed of $6.5 \mathrm{~mm} / \mathrm{min}$ to reach a maximum load the chair could experience $[5,21,22]$.

\section{Result and discussion}

\section{The evaluation of the specimens' behavior}

The mean values of the mechanical properties of the curved samples, such as MOE, MOR, and NMOR, are tabulated in Table 3. Results showed that the mechanically failed specimens rehabilitated using GFRP sheets recover their mechanical properties, such that there does not exist a significant difference for standard deviation, maximum load, and MOE, at a confidence level of $95 \%$.

Furthermore, the table shows the mean value of MOR for GFRP and tensile and compressive parts of the wood being 200.2, 77.73, and 126.4 MPa, respectively. Accordingly, based on MOR the failure of the specimens must start from the GFRP layer. Despite that, the experimental results, see Fig. 7, reveal that the failure of specimens began from the tensile part of the wood, where the mean value of NMOR is the highest 2.106 (Table 3). This fact reveals the capability of the proposed NMOR criterion for prediction of the failure region of composite structures.

Moreover, the force-displacement diagrams of primary and rehabilitated samples, Fig. 8, show the ultimate force carried by rehabilitated samples was more than what carried by non-rehabilitated samples. In adverse, the gradient of the force-displacement curve for the rehabilitated samples is less than the gradient of the force-displacement diagram for primary samples that it may contribute to their more flexibility.

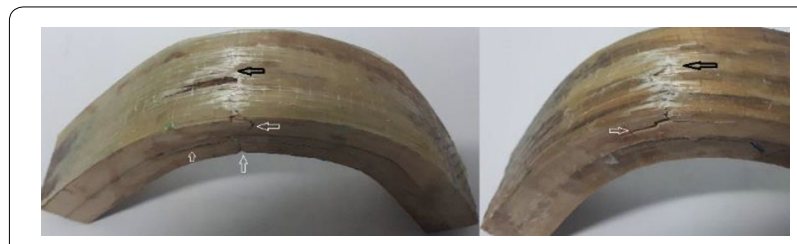

Fig. 7 Failure locations occurred in the wooden grain (white arrows) and GFRP (black arrows)

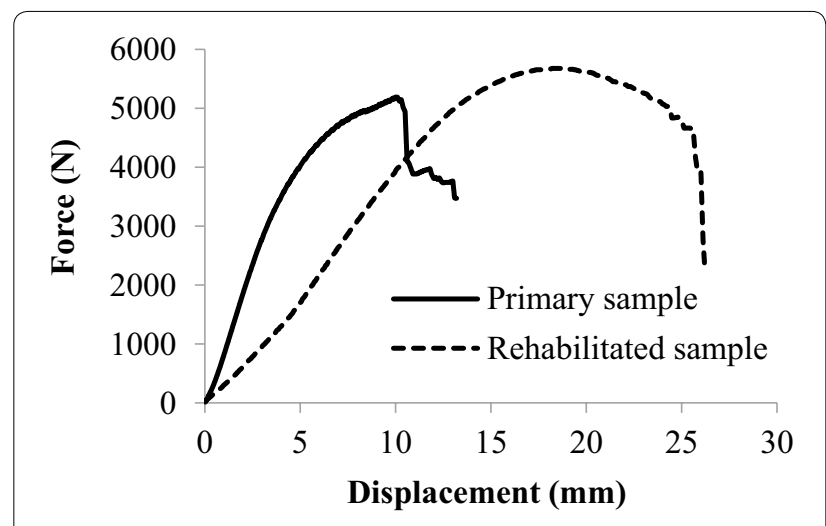

Fig. 8 Force-displacement diagrams of the specimens 


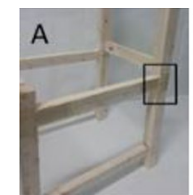

a

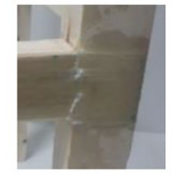

d

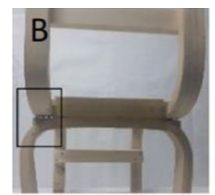

b

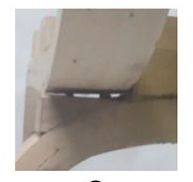

e

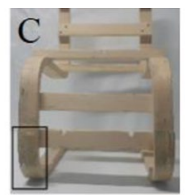

C

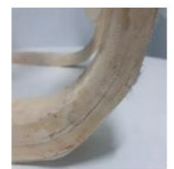

f1

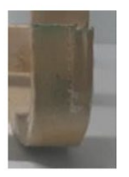

f2
Fig. 9 Illustration of failure locations of rehabilitated chair layouts $(\mathbf{a}-\mathbf{c})$; and their typical corresponding failure $(\mathbf{d})$ due to the fracture at a joint, e owing to the loosening of springs, and $\mathbf{f}$ due to the failure of wood in withstanding the tensile strength at the curved region

\section{The evaluation of the chairs' behavior}

The failure locations of the chairs depicted in Fig. 9 indicate that rehabilitated layout $A$ (RA) and rehabilitated layout B (RB) fail at the glued lanes. RA fails where the back post joins the seat rail (a corner joint), and $\mathrm{RB}$ miscarries just at the end of curved-repaired regions where the backside-unit leg connects to seatback. Additionally, the failure of pattern $\mathrm{C}$ occurs in the central of the lowest-curved parts of the frames. These phenomena are comparable with the study of [2]. The cracks and fractures at the curved failure regions and the separation at joints illustrate that the failure of all chairs occurs due to tensile stress. Therefore, GFRP sheets are under bending moments at the curved parts and tensile force at the joints.

Furthermore, the corner joints restrict the width and length of GFRP sheets to the dimensions of the connected parts, and hence, the bonding length between the sheets and wooden elements gets small. Whereas, the continuity of the frames at the curvatures provides a sufficient length for bonding. Also, the curves transfer the load without making stress concentration and make possible placing GFRPs at the farthest position from the neutral surface for using their high tensile resistivity.

Figures 10, 11 illustrate the force-displacement diagrams of the chairs. The rehabilitated layouts showed a distinct behavior, called "saw-tooth behavior". Its descending branch indicates the failure of farther wooden fibers due to the local buckling and/or cracking of the wooden material in compressive and tensile zones, respectively, and hence the decrease of the strength of the chairs. Moreover, the ascending branch reveals the re-distribution of the stress among the healthy fibers, causing the compensation of the loss or even the rise of the strength. Consequently, applying

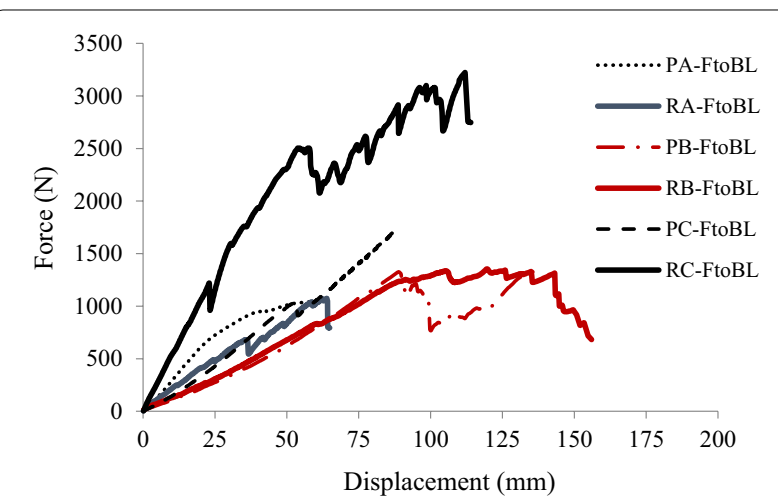

Fig. 10 The force-displacement diagrams of the chairs under FtoBL

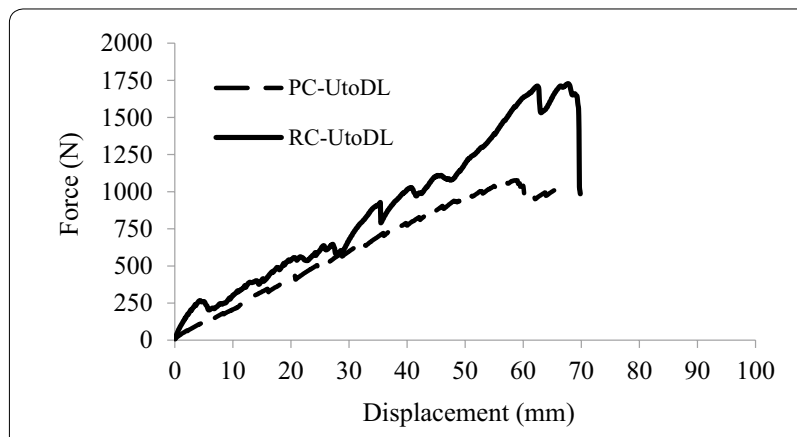

Fig. 11 The force-displacement diagrams of the chairs under UtoDL

Table 4 The mean values of the maximum loads carried by primary and rehabilitated chairs

\begin{tabular}{|c|c|c|}
\hline Chair patterns & Primary chairs & Rehabilitated chairs \\
\hline \multicolumn{3}{|c|}{$\begin{array}{l}\text { The mean values of the maximum loads under the FtoBL }( \pm \text { Std. devia- } \\
\text { tion) }(N)\end{array}$} \\
\hline A & 1019.7 (38.94) & $1152.7(176.7)$ \\
\hline B & $1421.3(151.2)$ & $1587.3(756.2)$ \\
\hline C & $1725.0(106.4)$ & $3837.3(674.7)$ \\
\hline \multicolumn{3}{|c|}{$\begin{array}{l}\text { The mean values of the maximum loads under the TtoDL ( } \pm \text { Std. Devia- } \\
\text { tion) }(N)\end{array}$} \\
\hline C & $1052.3(26.31)$ & $2154.7(374.3)$ \\
\hline
\end{tabular}

GFRPs accompanied by the curved design and structural integrity led to a high-performance layout.

The mean values of the maximum loads carried by chairs and their standard deviation under the FtoBL or UtoDL are shown in Table 4. Results showed that all rehabilitated chairs are more robust than the primary ones. It contributes to return the abandoned chairs to the utilization cycle and significantly reduces the demand for raw wood, strongly favored in economic-environmental aspects. The means values of the maximum loads (along 
with LSD test results) hierarchically decrease from layout C to layout A by the values of 2781, 1504, and $1086 \mathrm{~N}$. Without a doubt, this pertains to their degree of structural integrity. Besides that, the mean of the maximum load carried by RC-FtoBL is at least 2.4 times the ultimate loads of the other rehabilitated chairs. Moreover, rehabilitated chairs made by pattern $\mathrm{C}$ are 2.22 and 2.04 times, depending on FtoBL and UtoDL, respectively, more capable than the corresponding primary ones.

Univariate analyses of variance results, presented in Table 5, and LSD show that the mean differences of treatments are significant at the 0.05 level. One could see that the statistical differences between maximum loads of the chairs were insignificant at the $95 \%$ confidence level.

\section{Conclusion}

In this study, returning the poplar-wooden-discarding chairs for doing service was investigated by rehabilitation and the use of curved-integrated members in their frames. Depicting the behavior of rehabilitated-curved and primary-curved specimens showed that rehabilitating the failed wooden-curved specimens rebounds their mechanical properties, at least, as much as the primary-curved specimens by a confidence level of 95\%. Additionally, they are more deformable. Rebounding occurs due to the curvature of the specimen, which provides a sufficient length and a convenient adhesive surface bonding, transfers the applied load through tensile stress induced by bending moment, and makes possible placing the GFRP sheets at the farthest distance from the neutral surface and using their high tensile resistivity. The standard experiments conducted on chairs' patterns of $\mathrm{A}, \mathrm{B}$, and $\mathrm{C}$ illustrated that the sheets consolidate the fractured chairs such that they could carry a load higher than the mean maximum load experienced by primary chairs. Thus, the rehabilitation

Table 5 Results of variance analysis of the maximum loads related to the various designs of chairs

\begin{tabular}{llllll}
\hline Source & $\begin{array}{l}\text { Type III sum } \\
\text { of squares }\end{array}$ & Df & MS & $\boldsymbol{F}$ & S.g \\
\hline Corrected model & $1.612 \times \mathrm{E}^{7 \mathrm{a}}$ & 5 & $3.223 \times \mathrm{E}^{6}$ & 17.67 & 0.000 \\
Intercept & $5.771 \times \mathrm{E}^{7}$ & 1 & $5.771 \times \mathrm{E}^{7}$ & 316.5 & 0.000 \\
Chair & $9.356 \times \mathrm{E}^{6}$ & 2 & $4.678 \times \mathrm{E}^{6}$ & 25.66 & 0.000 \\
Rehabilitation & $2.907 \times \mathrm{E}^{6}$ & 1 & $2.907 \times \mathrm{E}^{6}$ & 15.95 & 0.002 \\
Chair and rehabilitation & $3.853 \times \mathrm{E}^{6}$ & 2 & $1.926 \times \mathrm{E}^{6}$ & 10.57 & 0.002 \\
Error & $2.188 \times \mathrm{E}^{6}$ & 12 & $1.823 \times \mathrm{E}^{5}$ & & \\
Total & $7.601 \times \mathrm{E}^{7}$ & 18 & & & \\
Corrected total & $1.831 \times \mathrm{E}^{7}$ & 17 & & & \\
\hline
\end{tabular}

$D f$ degree of freedom, $F$ statistical parameter calculated by mean squares (MS) $R^{2}=0.880$ (adjusted $R^{2}=0.831$ ) makes it possible to restore the chairs locally damaged to the utilization cycle and consequently to conserve natural resources, i.e., expounding lifespan of the product and eliminating negative environmental impacts.

Furthermore, the modified criterion, NMOR, proposed in this research clearly disclosed the NMOR provided a facility to predict the failure of composite wooden structures and even the wooden structures, having different strengths under tensile and compressive stress, while the MOR was not reliable in this case.

Moreover, RB withstands the mean maximum value of $3837 \mathrm{~N}$, which is about 3.3 and 2.4 times greater than RA and rehabilitated layout $C$ (RC), respectively. Also, $\mathrm{RC}$ is about $40 \%$ strengthener than RA, i.e., more integrity, more strength. Besides, pattern $B$ gets damage at curved regions, whereas patterns $\mathrm{A}$ and $\mathrm{C}$ get separation at the glued lane, where there is a joint connecting the back post and the seat-rail. That means the curved regions, the continuous curved members which exist in patterns $B$ and $C$ that are areas prone to fail, effectively provide the bonding length between GFRP sheets and wooden elements. On the other hand, rehabilitation conserves the unity of the frame through a re-distribution of stress among the healthy fibers and thus keeps the strength at a decent level, and the "saw-tooth behavior" emerges. Consequently, applying GFRP sheets and curved design along with structural integrity, provides a high-performance layout. Finally, univariate analyses of variance and LSD showed that the mean differences of treatments are substantial at the 0.05 level, and the statistical differences between maximum loads of the chairs were insignificant at the $95 \%$ confidence level.

\section{Abbreviations}

GFRP: Glass fiber-reinforcing polymers; FRP: Fiber-reinforcing polymers; CFRP: Carbon fiber-reinforcing polymers; PA: Primary layout A; PB: Primary layout B; PC: Primary layout C; RA: Rehabilitated custom chair; RB: Rehabilitated layout B; RC: Rehabilitated layout C; FtoBL: Front-to-back loading; TtoDL: Top-to-down loading; UTM: Universal testing machine; LSD: Least significant difference; ANOVA: A one-way analysis of variance; El: Flexural rigidity; MOE: Modulus of elasticity; MOR: Modulus of rupture; NMOR: Normalized MOR; Rehab.: Reveals the MOE is related to rehabilitated specimens.

\section{Acknowledgements}

We would like to express our gratitude to the University of Zabol, owing to financial grant (Grant No. UOZ-GR-9517-25) and using experimental facilities of the university.

\section{Authors' contributions}

MRHT, 25\%. AB, 25\%. MRM, 20\%. FK, 10\%. MRA, 15\%. NKM, 5\%. All authors read and approved the final manuscript.

\section{Funding}

Any third party or company did not fund the work.

Availability of data and materials

The datasets used and/or analyzed during the current study are available from the corresponding author on reasonable request. 


\section{Competing interests}

The rehabilitation of discarded chairs returns them to their service life, and massively reduces the demand for wood, which is strongly favored by environmental aspects. The use of curved members for designing chairs increases the integrity of chairs layouts and hence their strength. That means more integrity, more strength.

\section{Author details}

${ }^{1}$ Department of Civil Engineering, The College of Technology and Engineering, University of Zabol, P. O. Box: 98615-119, Zabol, Iran. ${ }^{2}$ Department of Paper, Wood Technology and Sciences, The College of Natural Resources, University of Zabol, Zabol, Iran.

Received: 7 February 2020 Accepted: 23 June 2020

Published online: 08 July 2020

\section{References}

1. Bayatkashkoli A, Hemmati T (2015) Effect of the number of joints and layer arrangements in components on the mechanical strength of chairs made from small diameter poplar. Int Wood Prod J 6(4):169-173. https:// doi.org/10.1179/2042645315Y.0000000014

2. Bayatkashkoli A, Ardakani M, Hosseini-Tabatabaei M-R, Madahi N (2017) Investigation of the maximum front to backload in the chairs made from curved and modified poplar wood. J Wood Sci 63(6):580-590. https://doi. org/10.1007/s10086-017-1650-3

3. Uysal M, Haviarova E, Eckelman CA (2015) A comparison of the cyclic durability, ease of disassembly, repair, and reuse of parts of wooden chair frames. Mater Des 87:75-81. https://doi.org/10.1016/j.matdes.2015.08.009

4. Eckelman CA (2003) Textbook of product engineering and strength design of furniture. Purdue University Press, West Lafayette

5. Eckelman C, Haviarova E (2006) Performance test of school chairs constructed with round mortise and tenon joints. For Prod J 56(3):51-57

6. Chang W-S (2015) Repair and reinforcement of timber columns and shear walls - a review. Constr Build Mater 97:14-24. https://doi.org/10.1016/j. conbuildmat.2015.07.002

7. Qi Y, Xiong W, Liu W, Fang H, Lu W (2015) Experimental study of the flexural and compression performance of an innovative pultruded glassfiber-reinforced polymer-wood composite profile. PLOS ONE 10(10):1-24. https://doi.org/10.1371/journal.pone.0140893

8. Singha A, Thakur VK (2008) Mechanical properties of natural fibre reinforced polymer composites. Bull Mater Sci 31(5):791. https://doi. org/10.1007/s12034-008-0126-x
9. Hojo T (2013) Durability of wooden members reinforced by carbon-fiber. Adv Mater Res 778:569-574. https://doi.org/10.4028/www.scientific.net/ AMR.778.569

10. Hameed N, Sreekumar PA, Francis B, Yang W, Thomas S (2007) Morphology, dynamic mechanical and thermal studies on poly(styrene-co-acrylonitrile) modified epoxy resin/glass fiber composites. Compos A Appl Sci Manuf 38:2422-2432. https://doi.org/10.1016/j.compositesa.2007.08.009

11. Sathishkumar T, Satheeshkumar S, Naveen J (2014) Glass fiber-reinforced polymer composites - a review. J Reinf Plast Compos 33(13):1258-1275. https://doi.org/10.1177/0731684414530790

12. Soltis LA, Ross RJ, Windorski DF (1998) Fiberglass-reinforced bolted wood connections. For Prod J 48(9):63-67

13. Raftery G, Kelly F (2015) Basalt FRP rods for reinforcement and repair of timber. Compos B Eng 70:9-19. https://doi.org/10.1016/j.composites b.2014.10.036

14. Jackson A, Day D (1995) Good wood joints. Harpercollins Publisher, London

15. Horwood R (1999) The Woodworker's Handbook. New Holland, London

16. Noll T (2007) Woodworker's joint book: the complete guide to wood joinery. Apple, UK

17. DIN (2006) DIN EN 1729-1, Furniture-chairs and tables for educational institutions_-part 1: Functional dimensions; German version EN 1729-1. German Institute for Standardization, German

18. DIN (2006) DIN EN 1729-2, Furniture-chairs and tables for educational institutions-part 2: safety requirements and test methods; German Version EN 1729-2. German Institute for Standardization, German

19. Yang $N$, Zhang $L$ (2018) Investigation of elastic constants and ultimate strengths of Korean pine from compression and tension tests. J Wood Sci 64:85-96. https://doi.org/10.1007/s10086-017-1671-y

20. ASTM (2005) ASTM D143-94: Standard methods of testing small clear specimens of timber. Standard methods of testing small clear specimens of timber. American Society for Testing and Materials (ASTM), West Conshohocken

21. Eckelman CA (1999) Performance testing of side chairs. Holz als Roh- und Werkstoff 57:227-234. https://doi.org/10.1007/s001070050047

22. Haviarova E, Eckelman C, Erdil Y (2001) Design and testing of environmentally friendly wooden school chairs for developing countries. For Prod J 51:64-68

\section{Publisher's Note}

Springer Nature remains neutral with regard to jurisdictional claims in published maps and institutional affiliations.

\section{Submit your manuscript to a SpringerOpen ${ }^{\circ}$ journal and benefit from:}

- Convenient online submission

- Rigorous peer review

- Open access: articles freely available online

- High visibility within the field

- Retaining the copyright to your article

Submit your next manuscript at springeropen.com 